Articles

Artículos 

EXEMPLARIa Classica

Journal of Classical Philology

$23,2019,13-36 \bullet$ ISSN 1699-3225

http://dx.doi.org/10.33776/ec.v23i0.3772

\title{
MÍMESIS DE UN DISCURSO JUDICIAL: USO - ¿Y ABUSO?- DE LA RETÓRICA EN EL MIMO 2 DE HERO(N)DAS
}

\author{
Claudia N. FernándeZ \\ Universidad Nacional de La Plata / CONICET \\ claudia.fernandez@conicet.gov.ar
}

\section{SUMMARY}

The judicial speech of Battaros -the only protagonist of Herodas' mime 2- is a sounding board for rhetoric topoi of Attic oratory. To go deeply into its connection with the forensic genre, we will evaluate to what extent this peculiar rhetor succeeds or fails in his persuasive purpose in the light of the assumptions provided by the Rhetoric to Alexander, but, above all, the Aristotelian Rhetoric.

KEYWORDS

Herodas, mime 2, judicial oratory, rhetoric

\section{RESUMEN}

El alegato de Bátaro, único protagonista del mimo 2 de Herodas, es caja de resonancia de numerosos lugares comunes de la oratoria ática. Para ahondar en esta relación con la oratoria forense, nos proponemos evaluar la adecuación -o inadecuación- de los medios de persuasión utilizados por este peculiar orador a la luz de los presupuestos vertidos para tales fines en la Retórica a Alejandro pero, sobre todo, en la Retórica aristotélica.

Palabras clave

Herondas, mimo 2, oratoria judicial, retórica

Fecha de recepción: 15/05/2019

Fecha de aceptación y versión definitiva: 07/08/2019 
El mimo 2 del poeta helenístico Herondas - probablemente un coetáneo de Calímaco y Teócrito en la corte ptolemaica de Alejandría- ${ }^{1}$ recrea el alegato de acusación de un tal Bátaro (Bó $\tau \tau \alpha \rho o s)$ en unos tribunales de la isla de Cos. Se trata del discurso de un único personaje protagonista, el dueño de un

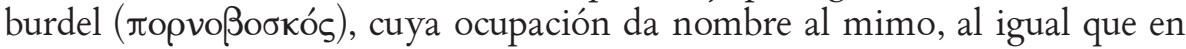
otras de las restantes ocho composiciones conservadas del mismo autor, cuyos títulos aluden a actividades o profesiones de sus protagonistas.

Estobeo llamó 'mimiambos' a estos breves poemas dramáticos, una forma de dar cuenta de su particular forma métrica que remeda el yambo escazonte de Hiponacte. ${ }^{2}$ Del mimo tradicional preserva, en cambio, su forma dialogada, que hace visible su carácter performativo, aunque no es del todo claro si estaban destinados a su efectiva representación o a la mera lectura. ${ }^{3}$

${ }^{1}$ La producción poética de Herondas se dio a conocer en 1891, con la editio princeps de los papiros que el Museo Británico recientemente había adquirido (F.G. Kenyon, Classical Texts from Papyri in the British Museum: including the newly discovered poems of Herodas, London 1891). Consistía esta edición de siete mimos completos y los tres versos iniciales de un octavo, reconstruido más tarde por el británico Knox, y publicado más o menos completo en 1922 (W. Headlam, \& A.D. Knox, Herodas. The Mimes and Fragments, Cambridge 1922).

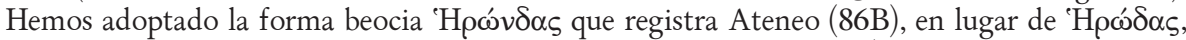

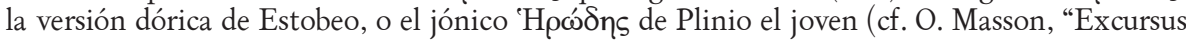
sur le nom du poète: Hérondas, plutôt qu' Hérodas et les noms en - $\omega ́ v \delta \alpha \varsigma,-\omega ́ v \delta \eta \varsigma ", R P h$ $48,1974,89-91)$. Datos internos a su obra dieron en suponer que vivió alrededor del 270 a.C. Precisamente la mención de la ciudad fenicia de Ace en este mimo 2 (16) nos permite suponer una fecha de escritura posterior al 266, ya que entre el 286 y el 266 la ciudad mudó su nombre por el de Ptolemais.

${ }^{2}$ La deuda con Hiponacte se extiende más allá del metro. El mismísimo Hiponacte se hace presente como personaje en el mimo 8 (cf. C. Fernández, "Herondas por Herondas: autoficción en el mimo helenístico", $A C 75,2006,23-92$ ). C. Miralles, "La poetica di Eroda", Aevum(ant) 5, 1992, 89-113, y sobre todo E. Degani, Studi su Ipponatte, Bari 1984, han señalado similitudes temáticas y léxicas entre ambos autores, y califican la producción herondea de mezcla del mimo tradicional y del yambo arcaico, un curioso cruce de géneros típico de la literatura erudita del Helenismo (cf. W. Kroll, Studien zum Verständnis der römischen Literatur, Stuttgart 1924).

${ }^{3}$ Cf. E. Esposito, "Herodas and the Mime”, in J. Clauss \& M. Cuypers (eds.), A Companion to Hellenistic Literature, Oxford 2010, 267-81: "Mimes, short compositions that focused on character portrayal and features of everyday life, offered poets the opportunity to observe aspects of the lower middle class, but filtered through the lens of a carefully defined and refined, 'aristocratic' art form." Que los mimiambos estaban destinados a un público lector fue la opinión de G. Pasquali, "Se i mimiambi di Eronda fossero destinati alla recitazione", in Xenia Romana, Roma-Milano 1907, 15-21, y G. Puccioni, Herodae Mimiambi, Firenze 1950, entre los primeros, y de L. Massa Positano, Eroda: Mimiambo II, Napoli 1971, y F-J. Simon, "Ta kyll' aeidein": Interpretationem zu den Mimiamben des Herodas, Frankfurt am Main 1991, más recientemente. Entre los defensores del carácter dramático de los mimiambos se destaca G. Mastromarco, Il pubblico di Eronda, Padova 1979, seguido, entre otros, por R. Hunter, "The Presentation of Herodas' Mimiamboi”, Antichton 27, 1993, 31-44. No hay acuerdo tampoco en determinar si su performance estaba a cargo de un grupo de actores o simplemente era una recitación monologada, como A. Melero, "Consideraciones en torno a los mimiambos de Herodas", CFC 7, 1974, 303-17, o I. C. Cunningham, Herodas. Mimiambi, Oxford 1971, prefieren suponer, adhiriendo a la tesis de Ph-E. Legrand, "Problèmes alexandrins II: à quelle 
En ese sentido el mimo 2 es un tanto original, pues Bátaro apenas si se ve interrumpido en los 102 versos en los que se extiende su exposición, cuando el escribano de la corte ( $(\rho \alpha \mu \mu \alpha \tau \varepsilon u ́ s)$ intenta, fallidamente, leer la ley de afrenta personal atinente al caso (46-8). El acusado es Tales $(\Theta \alpha \lambda \tilde{\eta} \varsigma)$, un rico capitán de barco, comerciante de granos, que ha violentado su burdel, con el afán de arrebatar a una de las mujeres. Tampoco lo de Bátaro es estrictamente un monólogo, porque su discurso está explícitamente dirigido a los jueces de la corte, que como personajes mudos ( $\kappa \omega \varphi \grave{~} \pi \rho o ́ \sigma \omega \pi \alpha)$ forman parte de la escena

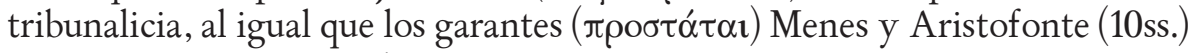
-tanto Bátaro como Tales son metecos y necesitan tener un representante ante el tibunal-, el acusado Tales, la prostituta Mírtale (65ss.), el encargado de la clepsidra (43) y el citado escribano (46ss.), todos presentes en el lugar.

Bátaro es un genuino exponente del tipo del 'rufián' o 'lenón', un personaje con importantes antecedentes literarios, sobre todo en la comedia media y nueva, ${ }^{4}$ y eso explica muchos de sus rasgos característicos, como la avaricia, la glotonería, la petulancia, la insolencia, y hasta su vejez. ${ }^{5}$ Pero si Bátaro nos ocupa en este trabajo es por aquello por lo que trasciende al tipo tradicional del lenón. Nos referimos concretamente a su competencia como orador, habida cuenta de la curiosa composición de su rhêsis, tratándose no solo del dueño de un burdel sino de un meteco, es decir, un extranjero sin derechos civiles, lo que no encuentra antecedentes históricos ni ficticios para comparar. ${ }^{6}$

Aun con el desvanecimiento de la democracia y de sus foros civiles, los griegos nunca dejaron de ser un pueblo litigante; persistían en las ciudades griegas del s. III a.C. las ocasiones propicias para practicar el arte de la retórica. Por mucho tiempo se supuso una disminución sustancial de su función, hasta devenir un formalismo vacío, un mero ejercicio escolar de sofisticado esteticismo. Hoy en día, en cambio, sabemos de su importante presencia a juzgar por la influencia que ejerció en diferentes géneros literarios, como la poesía y el drama - particularmente en Menandro-; aunque los testimonios de oratoria forense de esa época son casi nulos. ${ }^{7}$

spèce de publicité Hérondas destinait-il ses Mimes?", REA 4, 1902, 5-35.

${ }^{4}$ Hay rufianes en la comedia griega media y nueva, pero, por sobre todo, en la comedia latina. R. Hunter, "Plautus and Herodas", in L. Benz (ed.), Plautus und die Tradition des Stegreifspiels, Tübingen 1995, 155-69, relaciona muy especialmente el mimo II con Pseudolo de Plauto. En Rudens del mismo autor y Adelphoe de Terencio un lenón es llevado a juicio,

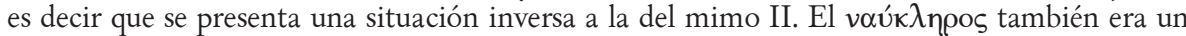
personaje tipo de la comedia nueva; de hecho da título a varias obras de Menandro. El epigrama helenístico lo presenta bruto y libertino (V. Barbieri, Eroda. Mimiambi, Milano 2016, 190).

${ }^{5}$ Cf. G. Zanker, Herodas. Mimiambs, Oxford 2009, 66-71.

${ }^{6}$ Se ha querido ver un antecedente en el fr. 104 de Sofrón, en el que se alude a un tal

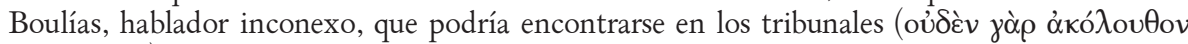

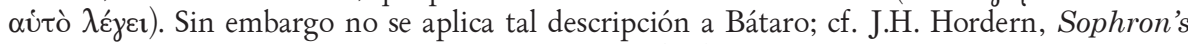
Mimes: Text, Translation, and Commentary, Oxford 2004, 186.

7 Tan solo nos han llegado dos papiros del s. III a.C. cuyo contenido certifica la plena 
Los estudiosos de la obra de Herondas, desde un principio, reconocieron que muchos de los recursos y estrategias persuasivas del rufián Bátaro reproducían lugares comunes de los discursos tribunalicios de los oradores áticos del s. IV, de quienes sí tenemos un repertorio vasto e ilustrativo. En consonancia con esta observación, y para ponderar en qué medida su alegato hace un buen uso de los dispositivos técnicos predicados en las escuelas de retórica de su tiempo, proponemos comparar los recursos presentes en su discurso con las propuestas vertidas en los manuales de retórica que, también del s. IV, han sobrevivido. Ellos son la Retórica a Alejandro (Rh.Al.), probablemente de Anaxímenes de Lámpsaco ${ }^{8}$ y, sobre todo, la Retórica aristotélica $(R h.) .{ }^{9}$ Podrá objetársenos la incertidumbre acerca de la circulación de los textos de Aristóteles luego de su muerte, antes de la edición de Andrónico de Rodas, pero no es nuestra intención postular, ni siquiera sugerir, algún tipo de relación directa entre Herondas y el Estagirita. Entendemos que los postulados de la escuela peripatética acerca de la oratoria debieron de llegar a los eruditos del Helenismo a través de Teofrasto y de sus discípulos. Teofrasto escribió sobre

actividad de las cortes. Nada ha sobrevivido en cambio de los oradores helenísticos Demócares de Leucónoe, Calícrates de Leoncio, Molón de Rodas o de los tratados de retórica escritos durante la época, aunque serían posteriores a la obra de Herondas. Las ciudades más importantes tenían escuelas donde estudiar retórica de alta competencia; véase al respecto J. Walter, Rhetoric and Poetics in Antiquity, Oxford 2000, 45ss.; J. Vanderspoel, "Hellenistic Rhetoric in Theory and Practice", in I. Worthington (ed.), A Companion to Greek Rhetoric, Oxford 2007, 128; Ch. Kremmydas \& K. Tempest (eds.), Hellenistic Oratory. Continuity and Change, Oxford 2013.

${ }^{8}$ Erróneamente atribuida a Aristóteles, casi todos coinciden, sobre la base de una referencia de Quintiliano, en adjudicarla a Anaxímenes de Lámpsaco (ca.380-320), tutor de Alejandro además del Estagirita. Habría sido escrita hacia el 340 a.C. De un carácter más práctico y menos filosófico que la Retórica de Aristóteles, ambos textos convergen en la separación de los géneros de la oratoria, en la división de las pruebas y en muchas de sus prescripciones. Sin embargo, discrepan en el sentido de parte de la teminología que comparten, lo que obliga a ser muy cautos a la hora de homologarlas. Es muy probable que sigan fuentes comunes. Cf., al respecto, P. Chiron, "The Rhetoric to Alexander", in I. Worthington (ed.), A Companion to Greek Rhetoric, Oxford 2007, 90-106: "The Rhetoric to Alexander (...) is a treatise with very practical ambitions. It is written for professional orators and is almost devoid of reflection on the definition of the discipline itself, its justification or even its function in the society of the time." Citamos por la edición de D. Mirhady, Rhetoric to Alexander, Cambridge (MA) 2011.

9 Aristóteles define la retórica como "la habilidad, en cada caso, de ver el medio de

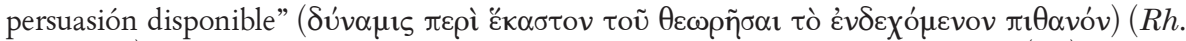
1455b25-6). P. Ricoeur "Between Rhetoric and Poetics", in A. Oksenberg Rorty (ed.), Essays on Aristotle's Rhetoric, Berkeley - Los Angeles - London 1996, 326, destaca el valor de la Retórica aristotélica frente al resto de tratados sobre el tema: "Aristotle's rhetoric constitutes the most brilliant of these attempts to institutionalize from the point of view of philosophy." Tal como nos ha llegado, se distinguen dos períodos en su escritura: el de la academia, alrededor del 350 a.C, y durante la segunda estancia del filósofo en Atenas, alrededor del 333. Sobre el destino del texto luego de la muerte de Aristóteles, véase G.A. Kennedy, "The Composition and Influence of Aristotle's Rhetoric", in A. Oksenberg Rorty (ed.), Essays on Aristotle's Rhetoric, 421ss. Citamos por la edición de G. Kennedy, Aristotle. On Rhetoric. A Theory of Civic Discourse, New York - Oxford 2007². 
temas de retórica y poética, divulgando las teorías de su maestro y ampliando especialmente en lo referente al estilo -Diógenes Laercio (5.24) le adscribe una veintena de obras sobre estas cuestiones-. Como es el tratado de oratoria más completo de su tiempo, la Retórica aristotélica constituye, a nuestro parecer, el texto idóneo para proveernos un patrón a partir del cual ponderar el discurso de Bátaro en tanto un caso de oratoria judicial.

De algún tipo de relación de Bátaro con los oradores áticos daría cuenta su nombre, que podría aludir al sobrenombre 'Bát(t)alos' que recibió el orador Demóstenes. Es un derivado del verbo $\beta \alpha \tau \tau \alpha \rho i ́\} \omega$ ("tartamudear"), cuyo reemplazo de la rho por la lambda imitaba el lambdacismo del ateniense. ${ }^{10}$ En este punto, el de interpretar el tipo de relación que establece el mimo II con la oratoria, las opiniones están divididas. Por un lado, los editores como Terzaghi ${ }^{11}$ o Miralles ${ }^{12}$ reconocen en él una sátira y reminiscencia de los discursos tribunalicios del s. IV, por otro lado están los que menosprecian la incidencia del afán paródico del mimo, para cargar las tintas más bien en la rica caracterización del personaje, como plantea por ejemplo Zanker en su edición, o antes Cunningham en la suya. ${ }^{13}$ Últimamente la cuestión se ha retomado. Destacamos, en tal dirección, el trabajo de Carey ("Pimps in Court"), un referente en el estudio de la oratoria ática, que releva en el discurso de Bátaro muchos de los topoi del género forense. El tipo de afrenta al que la querella de Bátaro adscribe también remite a un tipo frecuente de litigio originado por la pasión amorosa que acababa en algún disturbio callejero. Al fin y al cabo Tales, según Bátaro, está enamorado de la muchacha (79). Por lo demás, Herondas demuestra conocer las leyes y penalidades de su época, así como el estricto protocolo de las prácticas de las cortes atenienses: "it is Athenian procedural law transposed to Cos to create a fictive forensic world". ${ }^{14}$

${ }^{10}$ Cf. Hunter, "Plautus and Herodas", 163-4: "Battaros is therefore a 'lowlife' alter ego of the greatest Attic orator of the classical period”. Cf. D. 18.180 (Sobre la corona); Aeschin. 1.126, 131,(Contra Trimarco); 2.99 (Sobre la embajada fraudulenta); Plu., Dem. 4.5. En Esquines el sobrenombre de Demóstenes no se relaciona con su tartamudez sino con el afeminamiento y la vida disoluta, dos rasgos que curiosamente aparecen en Bátaro (Barbieri, Eroda, 62). Bó $\tau(\tau) \alpha \lambda$ os es también el nombre de un célebre flautista de Éfeso, del s. IV a.C., que calzaba zapatos femeninos y, por otro lado, el mismo término ßá $\tau \alpha \lambda$ os se usaba para referirse al ano. El nombre propio de Bátaro está atestiguado epigráficamente; cf. O. Masson, "En marge du mime II d'Hérondas: les surnoms ioniens Bó $\tau \alpha \rho \circ \varsigma$ et B $\alpha \tau \tau \alpha \rho \tilde{\alpha} \varsigma$ ", REG 83, 1970, 356-61; L. Di Gregorio, Eronda. Mimiambi (I-IV), Milano 1997, 114.

${ }^{11}$ N. Terzaghi, Eroda. I Mimiambi, Torino 1925.

12 C. Miralles, Herodes. Mimiambs. Text revisat i traducció de Carles Miralles, Barcelona 1970.

${ }^{13}$ Cf. Cunningham, Herodas, 81: "It is generally said that the piece is a parody of Attic court speeches, but this is to give the wrong emphasis. (...) his primary intention is not to

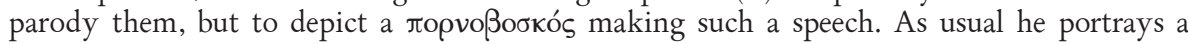
character."

${ }^{14}$ Ch. Carey, "Pimps in Court", in E. Harris, D. Leâo \& P. Rhodes (eds.), Law and Drama 
El alegato de Bátaro sigue el desarrollo básico y completo de la disposición

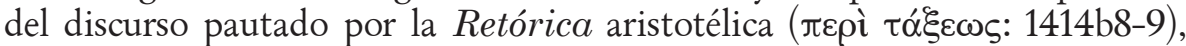
esto es: introducción $(\pi \rho o o i ́ \mu 10 v)$, que se podría extender hasta el v. 15;

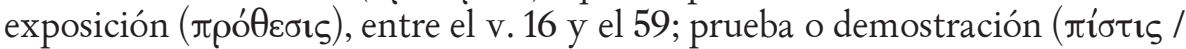

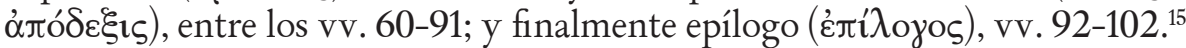

La introducción responde solo parcialmentea los parámetros aconsejados para los proemios forenses: construido sobre la base de una serie de consideraciones

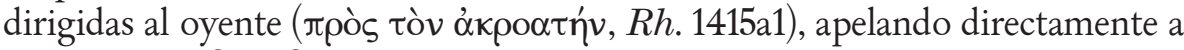
los jueces -ő $v \delta \rho \varepsilon \varsigma \delta ı \alpha \alpha \sigma \alpha \alpha i$ son las primeras palabras del mimo, como también las de muchas oraciones-, no anuncia sin embargo todavía el asunto (

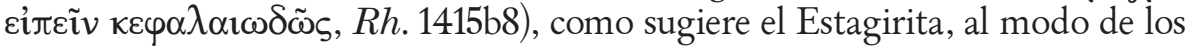
prólogos de los poemas épicos y dramáticos: ${ }^{16}$

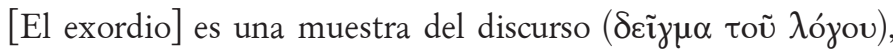
para que se sepa por adelantado acerca de qué trata el discur-

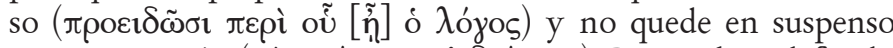

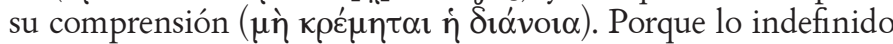



in Ancient Greece, London 2010, 174. Siguieron a Carey los trabajos de A. Maiuri, "Aspetti di parodia giudiziaria nel secondo mimiambo di Eroda”, Rivista di Diritto Ellenico 2, 2012,10731, y E. Hall, "Rhetorical Actors and Other Versatile Hellenistic Vocalists", in Ch. Kremmyda \& K. Tempest (eds.), Hellenistic Oratory. Continuity and Change, Oxford 2013, 109: "The oration itself closely adheres to the structure familiar from the surviving, canonical fifth- and fourth-century legal speeches concerned with similar crimes." J. Goeken, "Un souteneur à la barre: peinture de caractère et mise en scène déclamatoire dans le Mime II d'Hérodas", in H. Vial (ed.), Poètes et orateurs Dans l'Antiquité. Mises en scène réciproques, Clermont-Ferrand 2013, 201-19, se suma a esta lista.

${ }^{15}$ Aristóteles reduce a exposición y demostración las partes esenciales de todo discurso. En cuanto a la estructuración de la oración de Bátaro, no hay acuerdo de la crítica en la determinación de sus partes. Terzaghi (Eroda) distingue solo dos: la exposición (1-83) y la propuesta de orden jurídidico a los jueces, conclusión y peroratio (84-102). También Zanker (Herodas, 62) coincide en indicar el comienzo de la peroratio en el v. 84, con una nueva invocación a los jueces. S. Aquino, "El burdelero de Herodas: del discurso judicial real a la creación literaria”, in H. Beristáin \& G. Ramírez Vidal (ed.), La dimensión retórica del texto literario, México 2010, 51-64, propone, en cambio, que el exordio termine en el v. 5, la demostración en el v. 46, y el epílogo en el v. 72. Goeken, "Un souteneur à la barre", coincide en parte con nuestra propuesta.

${ }^{16}$ Una opinión contraria es la de Goeken, "Un souteneur à la barre, 203, quien considera que Bátaro anticipa el tema principal de su argumentación en el exordio: un hombre lesionado debe ser resarcido. A nuestro modo de ver, Bátaro solo advierte a los jueces acerca de la igualdad de todos a la hora de ser juzgados, al tiempo que intenta atraer su benevolencia. Solo se extiende en la descripción del modo de vida de ambos contrincantes.

${ }^{17}$ En la misma dirección se expresa la Retórica a Alejandro (1441b32-35): "En primer

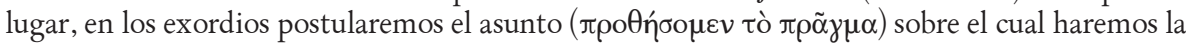
acusación o la defensa, como en las otras clases." Reconoce asimismo otro aspecto importante

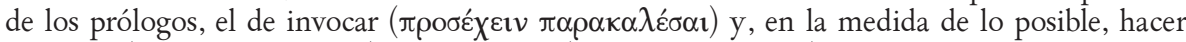

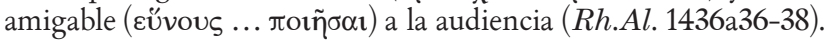




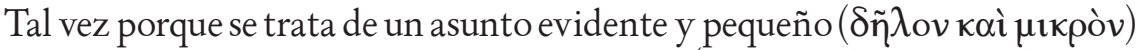

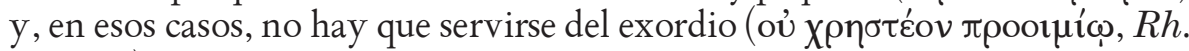
1415a24). La apelación a los jueces -1, 14, 26, 38, 49, 61, 68, 84, 85, 92- opera de elemento estructurador del discurso, inserta como está en los momentos clave en que se necesita llamar su atención: “(...) atraer la atención de los

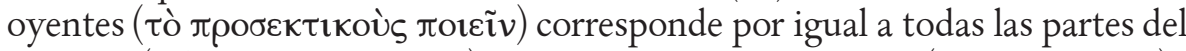
discurso ( $\pi \alpha ́ v \tau \omega \nu \tau \tilde{\omega} v \mu \varepsilon \rho \tilde{\omega} v)$, cada vez que sea necesario" (Rh. 1415b9-10).

Lo que se recoge en el espacio del prólogo es un lugar común de la oratoria judicial, el de reclamar la igualdad ante la ley de ricos y pobres (igual pedido en 21-4), o, para decirlo de otro modo, la familia, la riqueza y la reputación no deberían contar en la decisión de los jueces: ${ }^{18}$

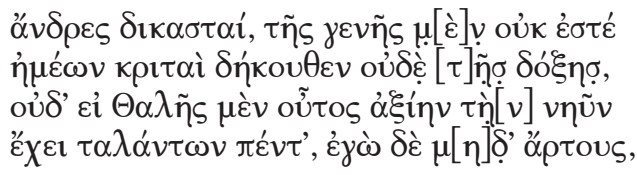

Señores jueces, no son árbitros

de nuestros orígenes, ni de nuestra reputación,

ni si el Tales este tiene un barco

que vale cinco talentos, pero yo ni pan... Herod. 2.1-4 $4^{19}$

No bien comenzada la exposición, Bátaro enzalsa sus virtudes cívicas enunciando los servicios brindados a la comunidad; vuelve a echar mano así de otra de las fórmulas transitadas por la oratoria ática. Es una forma recurrente de captatio benevolentiae, es decir, de atraer la simpatía de los jueces, como pueden testimoniarlo, entre muchos otros, Demóstenes 20.33-4 (Contra Leptines), cuando recuerda los servicios de quien envió granos en tiempos de escasez de trigo, o 34.38 (Contra Formión) en que también se menciona la provisión de granos a bajo precio como un servicio de lealtad a la polis.

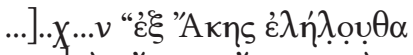

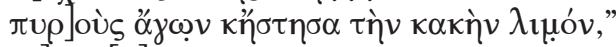

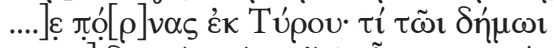

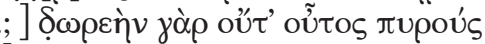

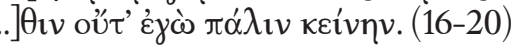

${ }^{18}$ Entre muchos otros ejemplos, véase D. 21.143 (Contra Midias), que recuerda a los jueces que no deben verse obligados a juzgar por el linaje, la riqueza o el poder.

19 Para Herondas disponemos de la excelente traducción al castellano de J.L. Navarro González \& A. Melero, Herondas: Mimiambos. Fragmentos mímicos. Partenio de Nicea: Sufrimientos de amor, Madrid 1981, publicada por la editorial Gredos. Hemos preferido, de todos modos, ofrecer nuestra propia versión de la totalidad de los textos griegos citados. 
[(Tales) tal vez nos dirá]: "He venido de Ace, transportando trigo, y puse fin a la espantosa hambruna”.

[En cambio yo,] putas desde Tiro. ¿No es eso nada para el pueblo? ${ }^{20}$ Porque este no regala el trigo [para triturar,] ni yo (regalo) a aquella.

La Retórica a Alejandro se explaya acerca de los términos en que el autoelogio debe ser expresado:

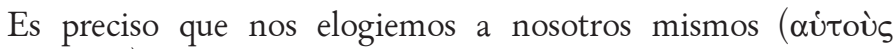

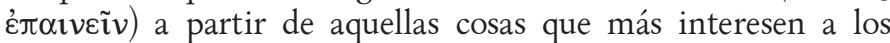

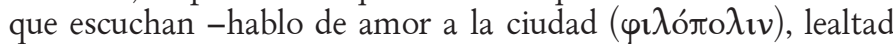

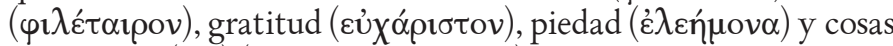
semejantes (...) (Rh.Al.1442a10-12)

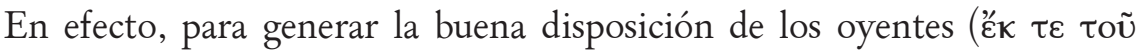

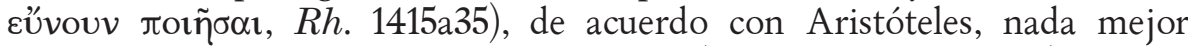

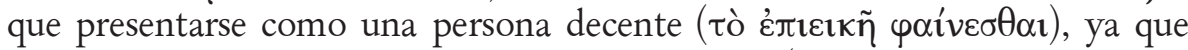

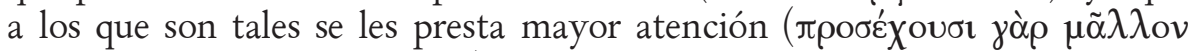

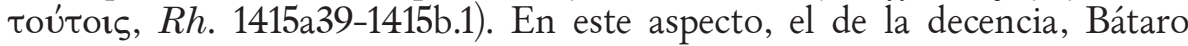
no la tiene fácil, pero sortea el obstáculo con pericia pues, ante la falta de virtudes que enumerar, se conforma con equipararse al acusado $-y$ esto a pesar de las desigualdades económicas que ya había señalado (3-4)-: insiste en que ambos son igualmente metecos (8), ninguno de los dos vive como quiere, sino como puede (9-10), y prestan, según vimos, similar servicio a la comunidad (16-20). Y tal vez podría agregarse que Bátaro se proclama superior a Tales, si el significado del nombre de su apoderado en el juicio,

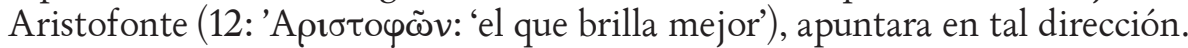
Como los apoderados eran elegidos por los metecos, estos últimos podían ser valorados por los heliastas de acuerdo con la reputación de los primeros. Al menos esa idea se expresa en Isócrates 8.53 (Sobre la paz): "consideramos que

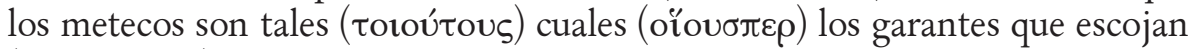
(’̀े vé $\mu \omega \sigma \imath) . " 21$

${ }^{20}$ Literalmente, “¿Qué es esto para el pueblo?" Hunter, "Plautus and Herodas", 164, encuentra un precedente de estas líneas en un fragmento de Filemón (3KA), donde un personaje desconocido valora el establecimiento de burdeles por parte de Solón.

${ }^{21}$ Di Gregorio, Eronda, 129, vincula la actividad de cada uno de los garantes con sus protegidos: Tales, que ha golpeado a Bátaro $(51,63)$, cuenta con un púgil victorioso, y Bátaro se vale de un ladrón, que amenaza con robar el manto del comerciante. Para Headlam, Herodas, el nombre Aristofonte podría haberlo tomado de Aristofonte de Azenia, un influyente jefe de gobierno entre 361 y 355 a.C., mencionado por Hipérides (En defensa de Euxenipo, 28). L. Bruzzese, "Una mantella misteriosa [Herod. Mim. 2.10-15], Prometheus 41, 2015, 155-70, en cambio, postula la posibilidad de que Aristofonte fuera en realidad Aristomedes, mencionado por autores cómicos y por Demóstenes en la Filípica 4. 
Bátaro ha ocupado la primera veintena de versos en hablar de sí mismo,

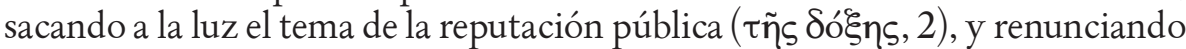
a contar el motivo de la acusación como era lo esperado. Procede, de acuerdo con la Retórica, como si fuese más bien un acusado y no un querellante. El rufián tiene razones para suponer que todo lo que diga puede objetarse a causa de su profesión marginal y bien hace entonces al refutar aquello que podría debilitar su acusación.

Para el que se defiende lo primero son las cuestiones atinentes

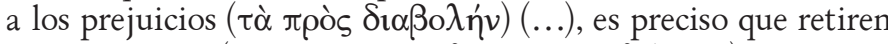

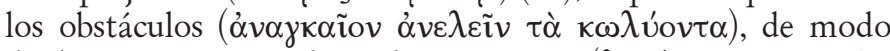

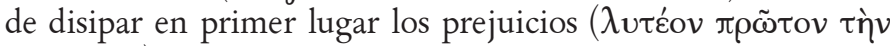
$\delta 1 \propto\left(\beta \mathrm{o} \lambda \eta^{\prime} v\right) . R h .1415 \mathrm{a} .29-33^{22}$

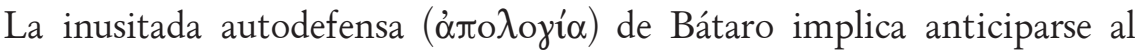
ataque prejuicioso del que Tales podría valerse para impugnar la validez de su demanda. Estamos ante otro recurso recurrente de la oratoria judicial,

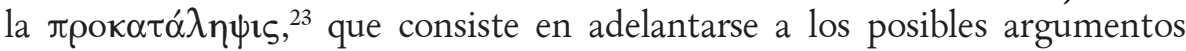
del adversario -ya lo había hecho también unas líneas antes imaginando la autopresentación de Tales como benefactor de su pueblo-. Anaxímenes, sobre todo, insiste en valorar la anticipación como un mecanismo estratégico eficaz para destruir las razones del contrario antes de ser pronunciadas.

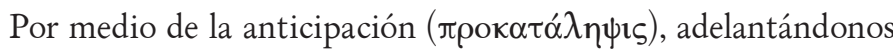

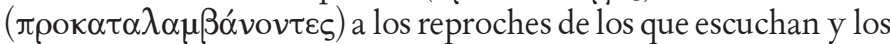
discursos de los que van a responder, quitaremos las dificultades

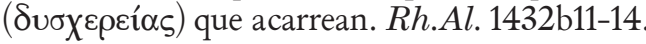

En los primeros discursos es preciso que, adelantándonos

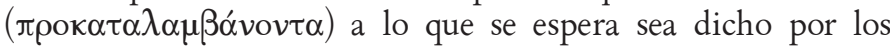
adversarios, desbaratarlo y debilitarlo. Rh.Al. 1433a36-8.

No ha pasado inadvertida la propensión a la exageración que caracteriza toda la exposición de Bátaro, tanto en lo que atañe a la descripción de los hechos ocurridos, como a la ponderación que hace de los mismos, como si se tratara de un ataque de proporciones descomunales. ${ }^{24} \mathrm{La}$ misma apreciación

${ }^{22}$ Esos prejuicios, de acuerdo con la Retórica a Alejandro, pueden ser acerca de la persona misma, de los hechos sobre los que se está hablando o del discurso, y provenir de circunstancias

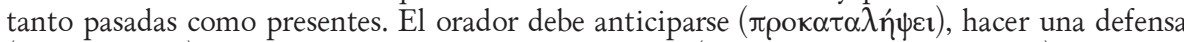

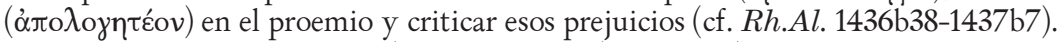

${ }^{23}$ Por ejemplo D. 21.160 (Contra Midias) o 38.25 (Contra Nausímaco y Jenopites), donde se pronostican las palabras de los adversarios, que hablarán sobre sus servicios al estado, respectivamente, triarquía y donación de trirremes.

${ }^{24}$ Cf. Zanker, Herodas, 66ss. 
vale para la descripción que hace de las condiciones de vida de ambos litigantes. Al respecto observa Redondo Moyano: "es poco probable que Bátaro pasara hambre -al menos Mírtale trabaja en su beneficio- y también que Tales fuese tan rico". ${ }^{25}$ Ciertamente Bátaro describe para sí una vida de indigencia (no tiene para comer [4], vive en el barro [23], arrastrando un pobre manto [23], con los zapatos podridos [23], y está muerto de frío [30]), ${ }^{26}$ mientras adjudica a Tales una opulenta riqueza (es un exportador de granos, dueño de un barco de cinco talentos [4] y viste una pelliza que le ha costado tres minas áticas $[22])^{27}$

Este apego a la exageración ha sido interpretado tradicionalmente como una nota peculiar del carácter rústico y tosco del personaje, y muy probablemente contribuya a perfilarlo como un típico rufián. Sin embargo, nada priva de ver también en la exageración una estrategia de persuasión. La hipérbole, el nombre técnico del procedimiento -tanto en su vertiente negativa cuando narra la pobreza del burdelero, como en la positiva cuando detalla la riqueza de Tales- favorece a considerar los recursos de vida de ambos contrincantes como arbitrarios e inmerecidos: ni Bátaro es tan malo como para ser tan desgraciado y padecer un ataque de parte de Tales -el burdelero fue duramente golpeado (63)-; ni Tales es un dechado de virtudes como para verse recompensado con tanta riqueza. A partir de estas consideraciones, logrará el burdelero seducir al auditorio, despertando en los que lo escuchan los sentimientos apropiados a los efectos de disponerlos con benevolencia para consigo y con hostilidad para con su adversario. Para decirlo con más exactitud, suscitará dos emociones clave en el ejercicio de la persuasión: la

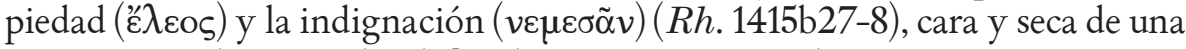
misma moneda, según las define la Retórica aristotélica:

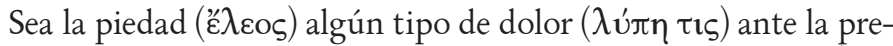

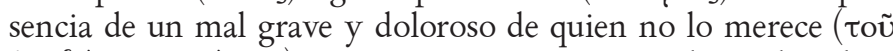

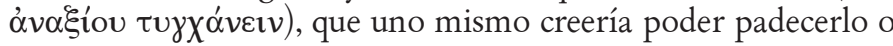
alguno de nuestros allegados. $R h .1385 \mathrm{~b} .12-5$

${ }^{25}$ E. Redondo Moyano, "Bátaro, un pornoboskos ante los tribunales (Mimo II de Herodas)", in Actas del VIII congreso español de estudios clásicos (Madrid, 23-28 de septiembre de 1991), Madrid 1994, 362 n. 2.

${ }^{26}$ Hemos traducido tpıßóv por "pobre manto" (típico de los filósofos, por ejemplo) para contraponer a la rica capa del navegante $(\chi \lambda \alpha i \tau v \alpha, 21)$. La imagen de pobreza también puede ser una forma de captatio benevolentiae; véase, por ejemplo, Lys. 32.16 (Contra Diogitón), donde se describe la pobreza de la viuda de Diódoto y sus hijos.

${ }^{27}$ El valor de la pelliza equivale al precio de un esclavo (cf. Herod. 5.21). Deberíamos suponer que su costo real rondaba los 20 dracmas, que es lo que vale una capa en Aristófanes ( $P l$. 982). Los cinco talentos que cuesta la nave, por su parte, equivalen a unos 30.000 dracmas, cuando en el s. V una nave similar costaba apenas 4.000 (cf. Redondo Moyano, "Bátaro, un pornoboskos", 362 n. 12). 
Se opone a sentir piedad principlamente lo que llaman indignación $(\nu \varepsilon \mu \varepsilon \sigma \tilde{\alpha} \nu)$. Porque sentir pena por las desgracias in-

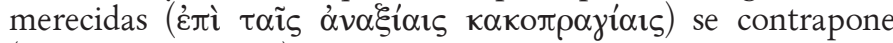

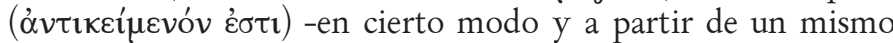
carácter-al hecho de sentir pena por los éxitos inmerecidos (غ̇ $\pi \grave{i}$

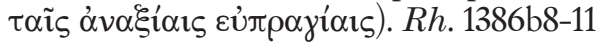

Aristóteles define las pasiones como "aquello por lo cual [los hombres]

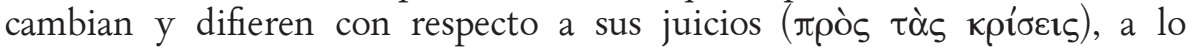

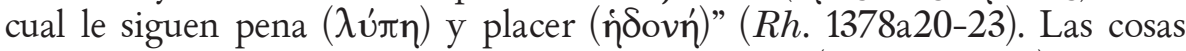

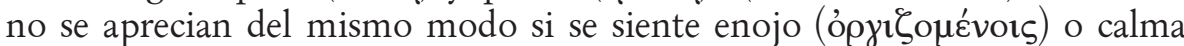

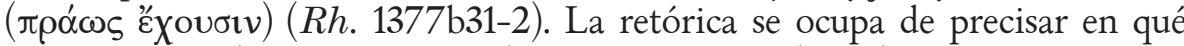

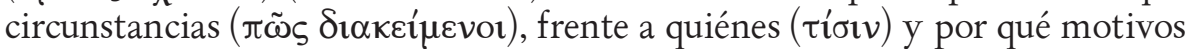

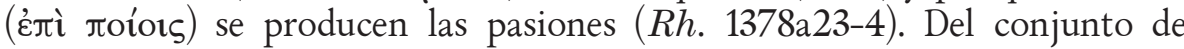
pasiones que Aristóteles analiza en su Retórica -un total de doce- la piedad y la indignación están estrechamente vinculadas con la idea de la justicia, en tanto se asientan en la consideración de si tal o cual individuo es merecedor o no de lo bueno o malo que le sucede y, en consonancia, predisponen a favor o en contra de los mismos. ${ }^{28}$ La detallada descripción que de las emociones nos brinda Retórica -siempre en referencia a quienes deben ser persuadidos, en este caso los jueces- resulta fundamental para valorar el componente retórico emocional del relato de Bátaro, pues los hombres difieren en su juicio de acuerdo con su condición emocional. Por medio de la hipérbole el rufián suscita la piedad con respecto a sí mismo y la indignación con respecto al acusado, y se asegura de ese modo la punición ejemplar que pide para este último.

Por otro lado, magnificando la gravedad de lo que le ha acontecido podrá acaparar mejor la consideración de los jueces. Observa Aristóteles:

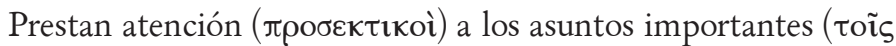

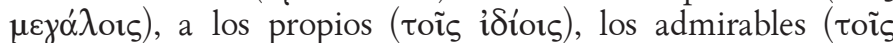

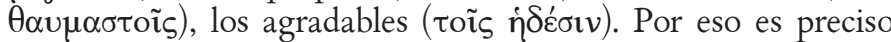
hacer ver que el discuso es acerca de tales cosas. $R h$. 1415b1-3.

${ }^{28}$ Cf. Rh.Al. 1443b17-19: "es necesario provocar en los jueces enemistad ("̌ $\left.\theta \rho \alpha v\right)$, cólera (ópỳ̀v) o envidia ( $\varphi \theta$ óvov) contra los adversarios, y amistad ( $\varphi \imath \lambda \hat{\alpha} \alpha v)$, gratitud ( $\chi \alpha ́ \rho \imath v)$ o piedad

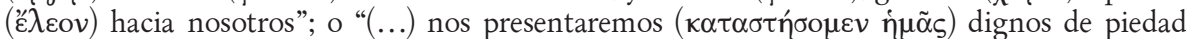

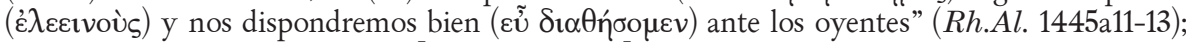

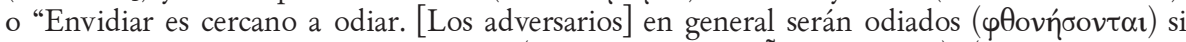

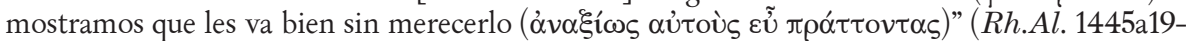
20). Es evidente que Anaxímenes llama 'envidia' lo que Aristóteles llama 'indignación'. Este último reconoce que ambas pasiones están emparentadas, pero las distingue; al respecto véase D. Konstan, The Emotions of the Ancient Greeks. Studies in Aristotle and Classical Literature, Toronto 2016, 111-28. 
Resulta adecuado, por esta razón, presentar una afrenta de tipo personal, como la que Bátaro ha sufrido a manos de Tales, como si constituyese un delito contra la comunidad toda. Con ese propósito, alerta que con el accionar de

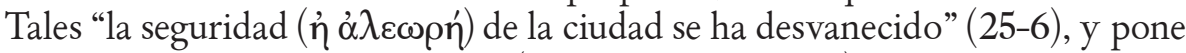

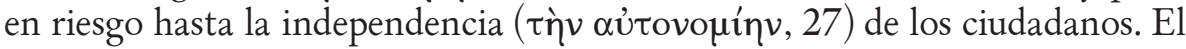
rufián procede tal como aconseja la Retórica a Alejandro, amplificando las implicancias del delito, de modo que se reconozca que su acusación redundará en el beneficio de muchos: "Te prestarán atención ( $\pi \rho 0 \sigma \varepsilon ́ \xi o v \sigma ı)$ si tienes entre manos acciones grandes ( $\mu \varepsilon \gamma \alpha \dot{\lambda} \alpha \varsigma)$ ), nobles ( $\kappa \alpha \lambda \grave{\alpha} \varsigma)$ y que convienen a

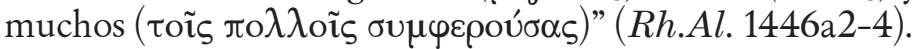

Al presentar la ofensa de Tales como un ataque contra los valores importantes de la ciudad en su conjunto, Bátaro está incluyendo a los jueces entre las víctimas. Es un modo eficaz de suscitar su cólera, por verse estos atacados en su propio honor. En efecto, el Estagirita define la coléra como "un

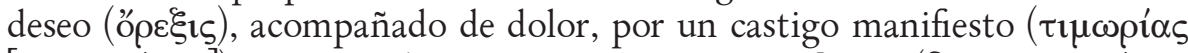
[

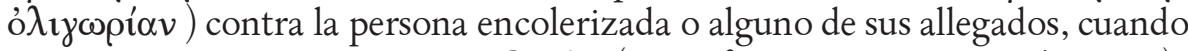

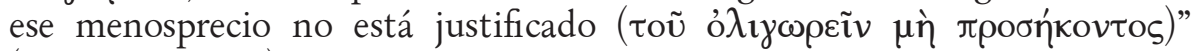
(Rh.1378a30-32). La cólera legitima el accionar de los jueces, de allí que los oradores áticos habitualmente argumentaran que la ofensa iba más allá de lo personal para convertirse en un daño de orden cívico: ${ }^{29}$ Demóstenes 21.7 (Contra Midias), por ejemplo, pretende demostrar que Midias no solo ha cometido un ultraje contra su persona, sino "contra los jueces, las leyes y todos los demás”, o en Lisias 1.47 (En defensa de la muerte de Eratóstenes) Eufileto pide a los jueces que no se juzgue su alegato como un pedido de venganza personal, sino en beneficio de toda la ciudad.

En el epílogo, espacio que opera habitualmente de resumen de la acusación, Bátaro retoma la misma idea de implicar a muchos en el perjuicio.

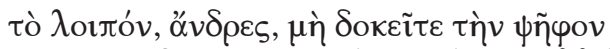

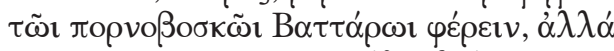

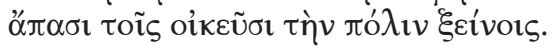

Por lo demás, señores míos, no crean que van a dar el voto

a Bátaro, el dueño del burdel, sino

a todos los extranjeros que habitan la ciudad. Herod. 2.92-94

${ }^{29}$ Cf. D. Allen, "Angry Bees, Wasps and Jurors: the Symbolic Politics of orgê in Athens”, in S. Braund \& G. W. Most (eds.), Ancient Anger. Perspectives from Homer to Galen, Cambridge 2003, 76-98: "Anger was valorized as a crucial judicial tool to such an extent that the ethics of anger constrained not only citizen behavior but also the ways in which institutions functioned in the city." 
En verdad, no hay necesidad para Bátaro de recordar a los jueces lo

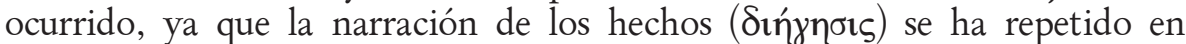
varias ocasiones a lo largo del discurso $(24-5,34-40,62-5) .{ }^{30}$ La repetición $\left(\pi \alpha \lambda_{\imath} \lambda \lambda_{\text {oý }} \alpha\right)$ es de suyo una suerte de recordatorio conciso, ${ }^{31}$ pero Bátaro se extiende brevemente cada vez, más o menos con las mismas palabras, aunque en una de las versiones el fuego alcanza solo a la puerta del burdel (63), mientras que en otra a la vivienda en su totalidad (36). Consideramos que estas contradicciones son menos una prueba de su torpeza, como sostienen, entre otros, Di Gregorio (Eronda) o Zanker (Herodas), que una muestra del interés por atraer la hostilidad contra el adversario. Pide la Retórica: "Debe narrarse


5). Sin embargo, la mera descripción del delito es insuficiente para persuadir, si los hechos no resultan creíbles o razonables. Los dos tratados coinciden en resaltar el valor de la credibilidad y la verosimilitud, el punto neural donde se pone en juego la habilidad del orador y que atañe a varios aspectos del discurso.

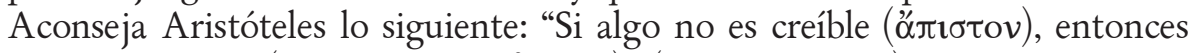
agregar la causa ( capitán de navío como Tales habría de violentar un burdel y raptar a una de sus prostitutas, si pagando hubiera podido tenerla? La advertencia de Bátaro a los jueces acerca de la condición de esclavo de Tales aporta credibilidad a su comportamiento. Para ocultar sus orígenes, el comerciante ha cambiado el nombre bárbaro de Artimmes (38) por el más noble de Tales. "Frigio" (37) lo llama el rufián, que es sinónimo de "sirviente", y el apelativo no se limita a ser un mero insulto o difamación, ${ }^{32}$ como cuando Demóstenes acusa a Esquines de mudar el nombre de sus padres (D. 18.130, Sobre la corona), ${ }^{33}$ sino que resulta relevante para volver razonable la conducta del navegante, ya que, como afirma la Retórica a Alejandro, la credibilidad de lo expuesto se asienta sobre la posibilidad o adecuación de lo ocurrido en relación con el carácter

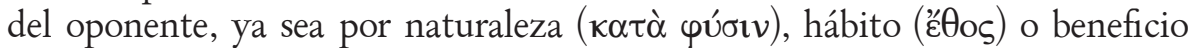



${ }^{30}$ Esto es, cómo fue golpeado a puñetazos (63), la puerta de su burdel despedazada (64), la casa incendiada con antorchas $(35-6,65)$, y una de sus muchachas arrebatada a la fuerza durante la noche $(24-5,36)$.

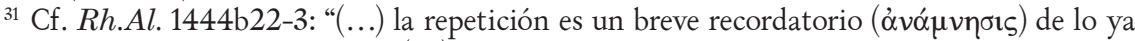
dicho; es útil en todas las ocasiones (...)"; véase también $R h . A l$. 1433b 29-33.

${ }^{32}$ De Frigia procedían gran parte de los esclavos; eran considerados unos bárbaros y la contracara de la valentía y la hombría. El nombre de Tales del marino mercante, por su parte, podría traer reminiscencias del filósofo Tales de Mileto, que también se dedicó al comercio.

33 Véanse otros ejemplos en Di Gregorio, Herodas, 119.

34 Anaxímenes también contempla la posibilidad de que un hecho ocurra a partir del componente emocional compartido con la audiencia; en esa dirección Bátaro justifica el rapto de la joven porque Tales está enamorado de ella (79). El Estagirita, por su parte, se ocupa de la naturaleza, los motivos y la disposición de ánimo de quienes delinquen en el libro 1 de su

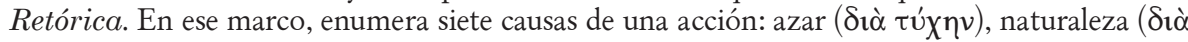




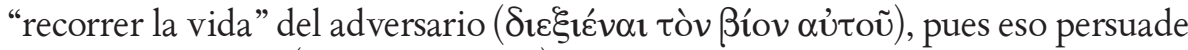
más que las burlas ( $R h . A l$. 1441b16): se explaya en el modo itinerante de vida de Tales, que lo priva de conocer cómo se administra una ciudad, al tiempo que desprecia la autoridad de las leyes (55ss.). ${ }^{35}$ Como afirma Aristóteles, la gente "no cree ( $\dot{\alpha} \pi \imath \tau \tau$ ṽ $\iota)$ que se pueda hacer otra cosa voluntariamente excepto lo

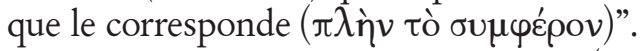

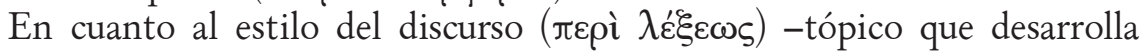
Aristóteles en el libro 3 de su Retórica- Bátaro cumple con la claridad que el

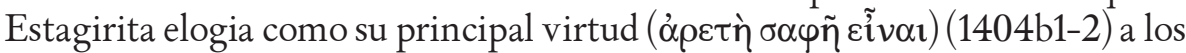

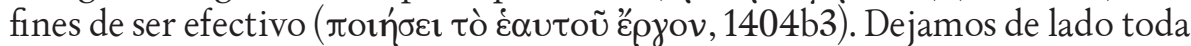
consideración acerca de la lengua del mimo, literaria y artificial, básicamente jónica en su ortografía y forma, con abundantes homerismos, dorismos, hapax legomena, y algunas otras formas raras, sello de la literatura erudita de la época, que no puede evaluarse en los mismos términos que un real discurso de corte.$^{36}$ Lo que sí es posible señalar es la presencia de aquellos recursos que el filósofo asigna a los textos elegantes, refinados ( $\tau \grave{\alpha} \dot{\alpha} \sigma \tau \varepsilon \tilde{\imath} \alpha)$; nos referimos a

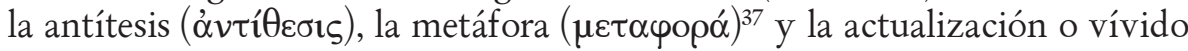

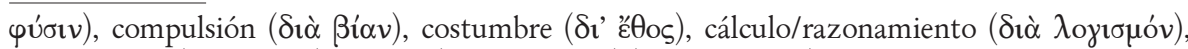

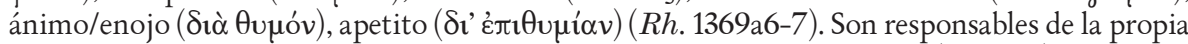
iniciativa, sin embargo, solo las acciones que responden a la costumbre $\left(\delta \imath^{\prime}\right.$ ' $ै \theta$ os) o al deseo

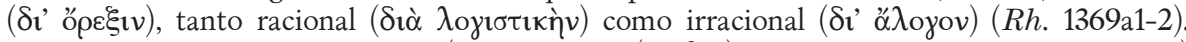
Ahora bien, la búsqueda del placer ("pues el deseo (ő $\rho \xi ı$ \&) es apetito de placer" $R h .1370$ a17-8) parece no ser suficiente, y el orador forense debe también rastrear la psicología de ciertos tipos humanos para dar las razones de un crimen (cf. A. Oksenberg Rorty, "Structuring Rhetoric", in A. Oksenberg Rorty (ed.), Essays on Aristotle's Rhetoric, 1-33).

35 "Vives hoy en Bricindera, ayer en Abdera, y mañana, si alguien te da dinero para el pasaje, navegarás hacia Fasélide" (Herod. 2.57-9). Bátaro nombra tres ciudades de connotación negativa, asociadas con lo incivilizado. Goeken, "Un souteneur à la barre", 201-19, llama la atención sobre el hecho de que Abdera fuera la patria del sofista Protágoras y Fasélide la del orador Teodectes. A su entender, la mención está al servicio de la estrategia de Bátaro de hacer de Tales un ejemplo de sofista.

${ }^{36}$ Podría señalarse cierta imitación del estilo de los oradores áticos en el uso de las partículas

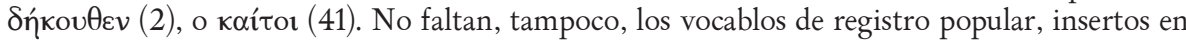
formas también populares, como la de los refranes. Esto puede deberse a la búsqueda cuidada de dar la impresión de naturalidad, esto es, a un 'uso literario' de los vulgarismos, fenómeno que también se produce a través de la parataxis o el uso de cláusulas parentéticas. Sobre la lengua de los mimos de Herondas, véase D. Bo, La lingua di Eroda, Torino 1963; sobre los tecnicismos jurídicos, Maiuri, “Aspetti di parodia giudiziaria”, 122 n. 64.

${ }^{37}$ Aristóteles define la metáfora en Poética 1457b6-9: "la metáfora consiste en dar a la cosa

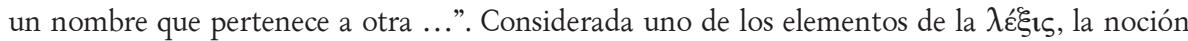
aristotélica de la metáfora no es exactamente la misma que adoptamos hoy en día. Tres virtudes

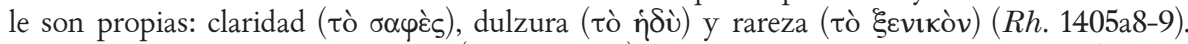
Ella es la que "pone ante los ojos" (Rh. 1410b33). Véase al respecto R. Moran, "Artifice and Persuasion: The Work of Metaphor in the Rhetoric", in A. Oksenberg Rorty (ed.), Essays on Aristotle's Rhetoric, 385-98, y P. Ricoeur, "Between Rhetoric and Poetics", in A. Oksenberg Rorty (ed.), Essays on Aristotle's Rhetoric, 324-84; este último es una versión abreviada de lo que expone en su afamado libro La métaphore vive, Paris 1975. 


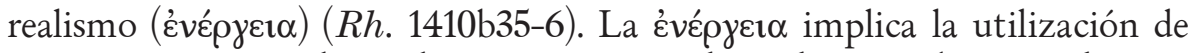
una imagen vivaz, de modo que quien escucha, o lee, perciba mentalmente los hechos como si los estuviera viendo por sí mismo. El término indica algún grado de actividad: lo descripto da la impresión de estar vivo y contribuye a la persuasión. El siguiente pasaje es una muestra de la combinatoria de los tres recursos aludidos, como el filósofo aconseja:

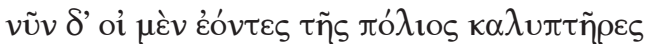

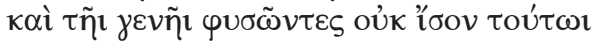

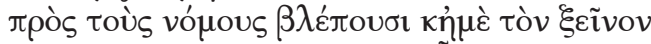

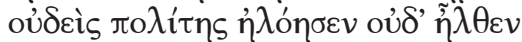

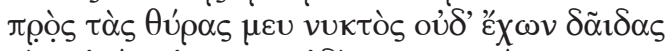

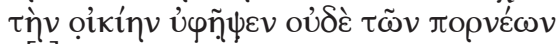 $\beta[i] \eta \imath \imath \alpha \beta \grave{\omega} v$ o"x $\chi \omega \kappa \varepsilon v$.

\begin{abstract}
Pero el caso es que los que son las tejas de la ciudad y resoplan de orgullo por su familia, más que este miran con respeto las leyes; y a mí, aunque extranjero, ningún ciudadano me apaleó ni se acercó a mi puerta durante la noche, ni con antorchas prendió fuego a mi casa, ni arrebató una de mis putas a la fuerza y se marchó. Herod. 2.31-7
\end{abstract}

Por medio de la antítesis se subraya la vileza de Tales, cuya conducta se opone a la de los nobles que han respetado al burdelero como al que más. A

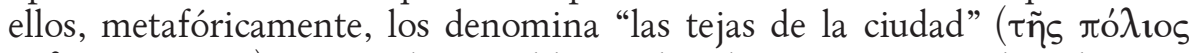
$\kappa \alpha \lambda \cup \pi \tau \tilde{\eta} \rho \varepsilon \varsigma, 31)$, asociando con el lugar elevado que ocupan en la polis. ${ }^{38} \mathrm{La}$ imagen se completa con otra nueva metáfora, la de los mismos ciudadanos con sus rostros insuflados de orgullo, cual flautistas en plena ejecución del instrumento. Estamos ante un notable ejemplo de la évépyeı $\alpha$ recomendada por el Estagirita, definida como lo dotado de movimiento ( $\dot{\eta} \delta$ '́vépyeı kívnoıs, $R h$. 1412a10). También es ilustración de lo que el mismo filósofo

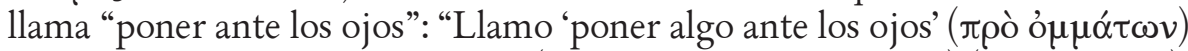

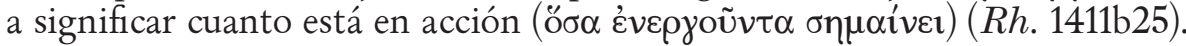
Las metáforas de este tipo son las preferidas por el filósofo, porque le dan dignidad al discurso y son una ocasión para aprender con facilidad (

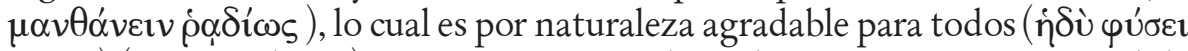
$\pi \tilde{\alpha} \sigma v v)(R h .1410 b 10-1)$. Forman parte también de su consejo más general de dar al lenguaje un tono fuera de lo común:

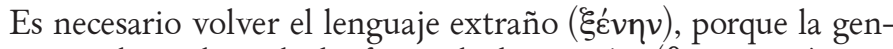
te es admiradora de lo fuera de lo común $(\theta \alpha v \mu \alpha \sigma \tau \alpha i ̀ ~ \tau \tilde{\omega} v$

${ }^{38}$ Hay otra oposición, además de la de nobles y vulgo, entre ciudadanos y extranjeros. 


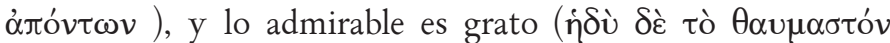

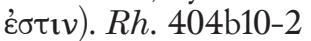

Para el Estagirita "también los proverbios ( $\alpha i \pi \alpha \rho o t \mu i \alpha \mathbf{i})$ son metáforas de unas especies a otras" ( $R h .1413 \mathrm{a} 17)$, y hay muchos proverbios 'metafóricos' en el discurso de Bátaro, como cuando dice: "sufrí a manos de Tales cuanto sufrió el ratón de Pisa" (62-3) en alusión al proverbio -también recordado por Demóstenes (50.26, Contra Policles)- usado para indicar la sumisión en la desgracia; ${ }^{39}$ o la frase "(...) habría escupido sangre como Filipo, el hijo de Brenco, una vez en Samos" (72-3), que remite a otro refrán acerca de un púgil que, aunque afeminado, ganaba siempre. ${ }^{40}$ Los ejemplos podrían multiplicarse. Los proverbios han sido siempre patrimonio de la cultura popular y también un elemento característico de la mimografía, según lo revelan los fragmentos de Sofrón, el creador del mimo literario. El tenor y registro de algunos de los refranes en boca de Bátaro reforzarían, por lo vulgar, este parentesco, como aquel que compara el agujero de la clepsidra con un "ano parlante" (Cunningham, Herodas, 91, "speaking anus"):41

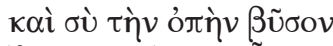

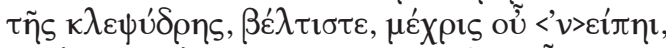

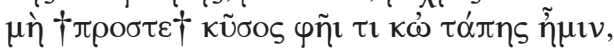

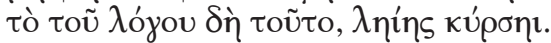

Y tú, amigo, tapa el agujero

de la clepsidra hasta que acabe de hablar, no sea que el culo tome antes la palabra y mi manta, como dice el refrán, se haga con el botín. Herod. 2.42-5 $5^{42}$

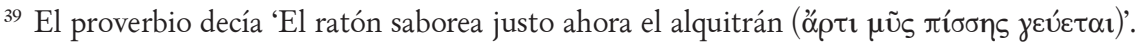
Probablemente derivara de una fábula, y el uso de fábulas como ejemplos es aconsejado también por Aristóteles (Rh. 1394a). El mismo proverbio se menciona en Teócrito (14.51) y, según Simon, "Ta kyll' aeidein", 37, la referencia de Herondas es un eco de este pasaje. Véase la detallada explicación que da Barbieri, Eroda, 196.

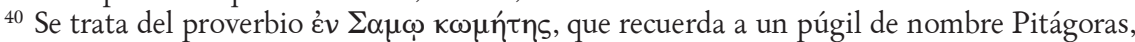
burlado por los adversarios por llevar el cabello largo.

${ }^{41}$ Cierra Bátaro su discurso (100-1) con la siguiente aseveración: "El frigio este les va a

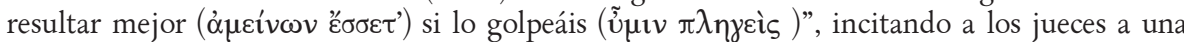
justa punición que mejore al reo (Di Gregorio, Eronda, 169). Hace referencia al refrán $\Phi$ ¡ò $\xi$

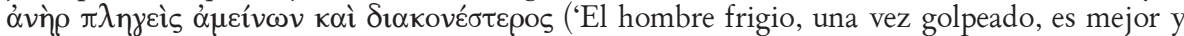
más servidor'). También la frase "Dando esto tendrás aquello" (80) podría ser la variación del proverbio 'Da y recibe al mismo tiempo'.

${ }^{42}$ La traducción de estas líneas ha sido muy discutida. Seguimos, para la nuestra, a Cunningham, Herodas, 91. Louis Laloy (J.A. Nairn \& L. Laloy, Herondas. Mimes, Paris $1960^{2}, 58$ ), en cambio, entiende 'deja que mi culo sufra y además mi manta sea robada' ("nous serons dépouillés jusqu’à la couverture"), siguiendo a P. Mazon, "Notes sur Hérondas", $R P h$ 54.2, 1928, 101-5. Di Gregorio, Eronda, 143-4, interpreta que Bátaro se asimila a la manta que sufre las consecuencias cuando no se deja a tiempo la cama para evacuar el vientre. El pedido 
Cercanas a los refranes son las sentencias o máximas, definidas por la Retórica a Alejandro como una explicación ( $\delta \dot{n} \lambda \omega \sigma \mathrm{s})$ de una convicción particular en relación con hechos en general ( $R h . A l$. 1430a40-1430b2). Hemos citado ya la sentencia de los vv. 9-10, "no vivimos como queremos sino como las circunstancias nos obligan ("₹ $\left.\lambda_{\kappa \varepsilon \imath}\right)$ ", es decir, "como podemos" (9-10), que encontramos formulada de modo muy similar en Menandro. ${ }^{43} \mathrm{La}$ Retórica recomienda emplear máximas como pruebas ( $\pi i ́ \sigma \tau \varepsilon \iota \varsigma)$ de verdad:

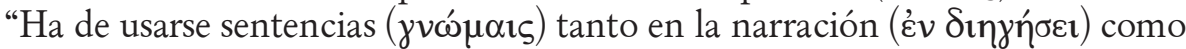

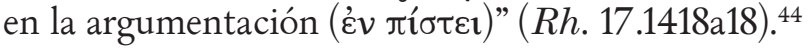

Aristóteles clasifica los argumentos o pruebas en dos grandes grupos: las derivadas del propio discurso, llamadas por el filósofo "retóricas" o "artísticas"

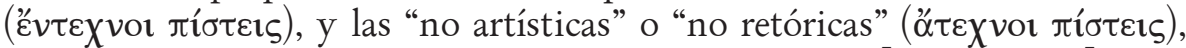
es decir, "aquellas que no son provistas por nosotros [los oradores], sino que preexisten, por ejemplo, testigos ( $\left.\mu \alpha \alpha^{\prime} \tau_{\nu \rho \rho \varsigma}\right)$, testimonios por tortura

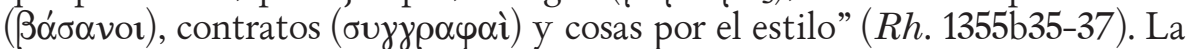
lista se amplía más adelante a los juramentos (ö $\rho$ ко ) y las leyes (vó $\mu$ or) $(R h$. 1375a24-5). ${ }^{45}$ De entre todos ellos, Bátaro se servirá solo de la básanos y de las leyes. En efecto, como no tiene testigos presenciales para presentar, se ofrece él mismo a ser azotado para dar testimonio bajo tortura. Se trata de la prueba por azote a la que se sometía a los esclavos como garantía de verdad y que solo podía usarse en juicios privados. ${ }^{46}$ Esta suerte de "autobásanos" de Bátaro no entraría en las posibilidades reales de un proceso porque no es él mismo un esclavo.

de frenar el paso del agua es habitual en los discursos forenses (cf. D. 54.36, Contra Conón).

${ }^{43}$ Cf. Menandro, fr. 47 KA, 6.2.67 de Andria. También en D. 57.31 (Contra Eubúlides) se habla de "vivir no del modo que quisiéramos".

${ }^{44}$ Cf. Rh. 1394a21-26: "Una máxima es una declaración, no ciertamente acerca de

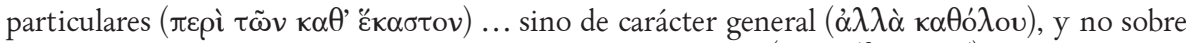

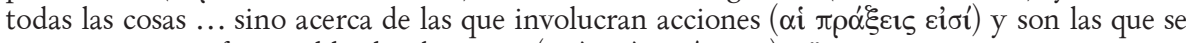

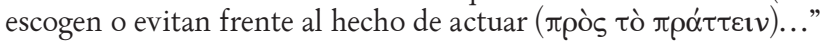

${ }_{45}$ De modo diferente clasifica Anaxímenes las pruebas: "Hay dos tipos de pruebas: unas resultan de los mismos discursos, los hechos y los hombres, otras son suplementarias a lo que

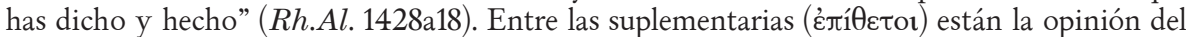

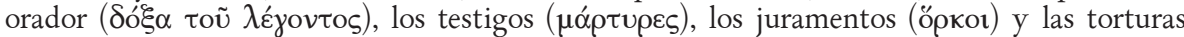
( $\beta \alpha ́ \sigma \alpha v o u)(R h . A l .1431 b 9-1432 \mathrm{~b} 4)$. Como se ve, no incluye las leyes, aunque podrían equivaler a la opinión del orador; para Mirhady, $R h$. $A l$., no es del todo evidente. Sobre el tratamiento de las leyes en la $R h . A l$. en el marco de su consejo de anticiparse al oponente, cf. 1443a11ss.

46 Aristóteles llama básanos a un tipo de testimonio, en tanto Anaxímenes la define como la forma de corroboración a partir de alguno que tiene el conocimiento pero no quiere manifestarlo (Rh.Al.1432a12ss.). De acuerdo con los testimonios, el litigante podía ofrecer a su esclavo para que fuera interrogado por medio de la tortura; si bien lo entregaba al oponente, podía controlar cómo procedía. El esclavo conocía la verdad y la tortura aseguraba que la dijera. Sobre los alcances de la básanos -si un testimonio o simplemente un desafío- y los ejemplos que proveen los oradores áticos, véase D. Mihardy, "Torture and Rhetoric in Athens", JHS 116, 1996, 119-31. 
En cuanto a las leyes, su efecto persuasivo residía en el hecho de convencer a los jueces del respaldo legal del litigante, quien era el que debía ocuparse de presentarlas como cualquier otra documentación, ya que no existía ningún libro que las contuviera y los jueces podían de hecho desconocerlas, aunque juraban dar su veredicto de acuerdo con ellas. ${ }^{47} \mathrm{El}$ encargado habitual de leer las leyes era el escribano, a quien precisamente Bátaro encarga la lectura de la ley de Carondas. ${ }^{48}$ Sin embargo, es el rufián quien termina su lectura ante el tribunal, enumerando penas y castigos. Podría suceder, como propone Di Gregorio (Eronda, 150), que estuviera mezclando diferentes regulaciones: la

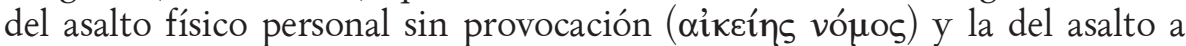

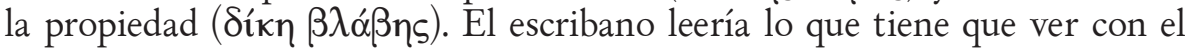
daño sufrido por Mírtale, en cambio Bátaro extendería la ley a lo acontecido sobre sus bienes y sobre su persona. No sería descabellado tampoco pensar que lo expresado por Bátaro sea una invención personal a partir de los códigos vigentes en su época. ${ }^{49}$

Una mención especial merece, en este desarrollo, el golpe de efecto que significa la exhibición ante el tribunal de Mírtale, la prostituta arrebatada del burdel, para que, desnuda, ponga en evidencia las señas de la violencia del maltrato. ${ }^{50}$ Muy probablemente estemos ante una recreación burlesca de la famosa anécdota que tiene como protagonista a la cortesana Friné, defendida por el orador Hipérides, quien, acusada de impiedad por uno de sus amantes, descubre su pecho para conseguir la indulgencia de los jueces ${ }^{51}$ La versión

47 También Anaxímenes aconseja enunciar las leyes que sostienen el caso y criticar las del oponente (Rh.Al.1443a12ss.). De ese modo proceden efectivamente los oradores forenses (cf. D. 21.46 (Contra Midias): "nada hay como oír el texto mismo de la ley"). Aunque formalmente las leyes eran otro medio más de persuasión, su estatus era especial: se penalizaba la presentación de leyes no existentes. Sobre la retórica de las leyes en Aristóteles, véase Ch. Carey, "Nomos in Attic Rhetoric and Oratory", JHS 116, 1996, 33-46.

${ }^{48}$ Carondas fue un famoso legislador del s. VI a.C., autor de los códigos de ciudades de la

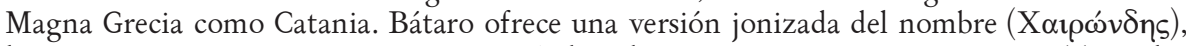
lo que no constituye necesariamente un índice de su ignorancia como interpreta Terzaghi, Eroda, 40. R. Di Virgilio, "La firma di Eroda", BollClass 9, 1988, 100-4, postula que en la mención distorsionada del nombre Herondas introduce su firma al final del trímetro precedido por $\kappa \alpha$ í.

49 En Atenas el monto de la compensación monetaria era reclamada por el demandante y los jueces finalmente decidían. En cambio en el código de Zaleuco, a menudo vinculado con el de Carondas, las penas estaban fijadas, como supone Bátaro. Tampoco era inusual postular el doble de la pena (cf. D. 21.43 (Contra Midias): se pide pagar el doble de la pena por un daño que fue voluntario). Carey, "Pimps in Court", 173, cree que probablemente estemos ante un conjunto de prescripciones legales, pero no ante un código legal real.

${ }^{50}$ El nombre significa "mirto" y designa vulgarmente la vagina, por lo que tiene, como muchos de los nombres de plantas, connotaciones obscenas; cf. J. Henderson, The Maculate Muse. Obscene Language in Attic Comedy, Oxford 19912, 134-5. También en el mimo 1(89) la alcahueta nombra a una cortesana llamada Mírtale. En cuanto a la exhibición de un esclavo durante el juicio, cf. D. 37.44 (Excepción contra Panténeto).

${ }^{51}$ Para Carey, "Pimps in Court", 178, Bátaro reproducía efectivamente en esta escena uno de 
de esta treta nos ha llegado a través de Ateneo (Deipnosophistai 13.590.e) y Posidipo (fr. 13KA) y podría ser una invención de la que Herondas se hace eco, y no un hecho histórico real. Tanto en Herondas, como en Hipérides, la exhibición de Mírtale apela a las emociones menos santas de los jueces. Tratándose de Bátaro, puede leerse además como la efectiva oferta del rufián que vende el servicio de una de sus mujeres; procurarse nuevos clientes sería una manera de verse resarcido de las pérdidas. Imposible no sonreír ante la presunción de que la depilación púbica de la muchacha, una práctica común en las mujeres de la época, se debía al atropello de Tales. El tratamiento cortés dado a la prostituta, como si fuera una joven doncella -le aconseja: "Para nada te avergüences. Piensa que estás mirando a tus padres y hermanos en estos jueces que ves”, 66-8)- está al servicio del humor característico de estos mimos que suelen tratar con seriedad y dignidad aquello que es tenido por procaz o vulgar, y viceversa. ${ }^{5}$

Volvamos, por último, a los modos específicamente retóricos o técnicos

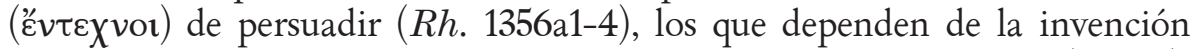
del orador. Aristóteles los limita a tres: 1. la argumentación lógica ( $\lambda$ óyos),

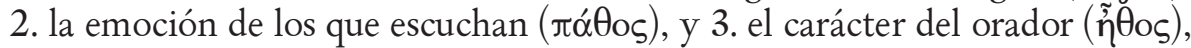
y los tres interactúan en conjunto. ${ }^{53}$ En lo que antecede, hemos discurrido principalmente acerca de cómo el alegato de Bátaro responde exitosamente

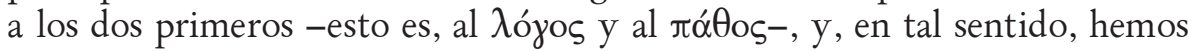
observado que el burdelero elige con criterio y oportunidad muchos de los recursos que los manuales de retórica aconsejan a los fines de convencer al

los más famosos golpes de efecto apócrifos del sistema legal ateniense. No puede desconocerse tampoco, tal como apunta Hall, "Rhetorical Actors", 111, que se trata de una escena típica de comedia: "The slave-woman who is displayed naked, so that her depilated genital area can be inspected, is however perhaps more reminiscent of the allegorical females and prostitutes in Old Comedy, for example Reconciliation in Aristophanes' Lysistrata and the depilated dancing girls offered to Xanthias at Frogs 516."

${ }^{52}$ En algunos casos, bajo la pseudo-simplicidad del texto se descubre un artificio subyacente acorde con los patrones de escritura de la época. Con respecto a este mimo en particular, véase el reciente trabajo de N. Piacenza, "Callimaco, Apollonio ed il tentado furto de Mirtale: un proceso por plagio nel Mimambo 2 de Eronda”, Eirene 52, 2016, 323-39, en que el autor propone una lectura en clave metaliteraria: Bátaro representaría alegóricamente a Calímaco, quien acusa a Apolonio de Rodas (Tales), del robo de elementos de su poesía (Mírtale), tal vez aludiendo concretamente a Las Argonáuticas. Piacenza funda detalladamente su hipótesis que sin duda enriquece las posibilidades interpretativas del mimo sin negar una lectura más literal como la que proponemos. Otras lecturas dedicadas a descubrir referencias encubiertas en los mimiambos fueron las de J. Stern, "Herodas' Mimiamb I", GRBS 22, 1980, 161-5; y "Herodas, Theocritus and the Urban Mime”, in Actas del XIII Simposio Nacional de Estudios Clásicos, La Plata 1997, 19-23.

53 "De las pruebas provistas por el discurso hay tres especies: unas están en el carácter (

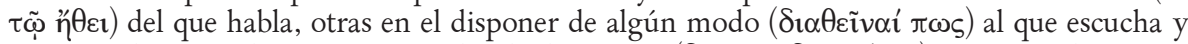

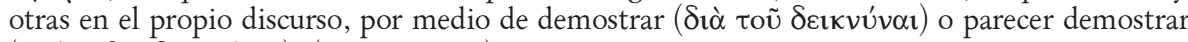

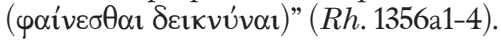


auditorio del carácter justo de un litigio. ${ }^{54}$ Sin embargo, por alguna razón que ahora nos proponemos determinar, su técnica oratoria no resulta del todo satisfactoria. Bien lo ha expresado R. Hunter, entre otros, cuando advierte que el discurso de Bátaro es por un lado un "desastre", pero por otro una "obra maestra". ${ }^{55}$ La mayoría de los estudiosos del mimo 2 ha localizado el problema en la imposibilidad de conciliar, en un mismo personaje, el tipo social $-y$ literario- del lenón, dueño de un burdel, con el rol del orador. Y, en el marco de esa propuesta de lectura, por tratarse de una figura amoral y de bajo estatus, suelen calificarse de banales en su boca los que son los motivos estándares de los textos canónicos de los oradores áticos. ${ }^{56}$ Nuestra propuesta, en cambio, pretende explicar el desempeño poco convincente de Bátaro como orador sin apartarnos de los preceptos de las retóricas que hemos venido comentando. A nuestro modo de ver, la clave reside en el tercero de los modos de persuasión arriba enumerados, esto es, en el $\tilde{\eta} \theta o s$, según lo concibe el propio Aristóteles.

Cuando el Estagirita habla del $\tilde{\eta} \theta$ os como medio de persuasión artística no se está refiriendo a la reputación externa que se tenga del orador, sino a la manifestación del carácter que se desprende de la forma en que este se presenta en su discurso, sobre todo en lo que dice de sí y no tanto en cómo lo dice. El Estagirita no estaría pensando en el estilo o en la forma de la exposición, sino en lo que piensa el que habla y el contenido de su discurso (Kennedy, Aristotle: On Rhetoric, 38 n. 39):

[Hay persuasión] por medio del carácter ( $\delta i \grave{~}$ toũ $\dddot{\eta} \theta$ ous) toda vez que el discurso se exprese de forma tal que haga creí-

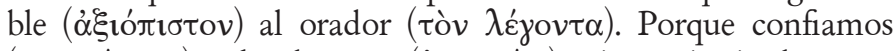

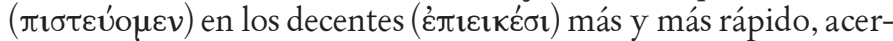
ca de todos los temas en general, y absolutamente ( $\pi \alpha \nu \tau \varepsilon \lambda \tilde{\omega} \varsigma)$ acerca de aquellos en los que no hay exactitud (

${ }^{54}$ Una opinión contraria a la nuestra es la de Goeken, "Un souteneur à la barre", que entiende que, aunque el discurso pretende ser serio, el rufián comete demasiados errores: mala gestión del tiempo, mal desarrollo de las partes del discurso, gusto por la digresión. Goeken cataloga la retórica de Bátaro de balbuceante, jugando con el sentido que tiene su nombre. Nos parece que todos los errores señalados por el autor resultan subjetivos y asentados sobre las consideraciones de una retórica grecolatina concebida con una mirada amplia, que contempla diversos autores como varios siglos de formulación.

55 "At one level the speech is a disaster; at another, it is a masterpiece" (Hunter, "Plautus and Herodas", 163).

${ }^{56}$ Cf. Barbieri, Eroda, 62, o Zanker, Herodas, 68. R.G. Ussher, "The Mimic Tradition of 'Character' in Herodas”, QUCC 21, 1985, 45-68”, se expresa en la misma dirección, cuando señala que este orador, poco educado, no consigue despertar la piedad con un fárrago de fórmulas y topoi sin orden ni coherencia. En las antípodas, B. Veneroni, "Ricerche su due Mimiambi di Eroda", RIL 105, 1971, 223-42, da por sentada la seriedad de la oratoria de Bátaro y su inconciencia con respecto a su propia miseria moral; relaciona con una sensibilidad epocal nueva en la valoración del individuo. 
duda ( $\tau$ ò $\alpha \mu \varphi \imath \delta o \xi \varepsilon \varepsilon \tilde{\imath} v)$. Es necesario que esto ocurra a través del

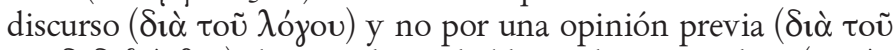

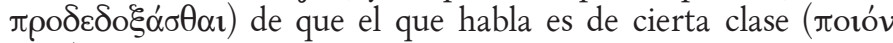
$\tau \imath v \alpha)$. Porque no ocurre, como algunos de los autores proponen

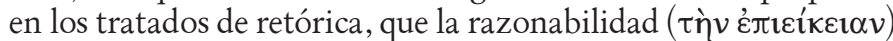
del que habla no aporta nada a la persuasión $(. .).(R h .1356 a 5-13)$

Según el Estagirita, como queda expuesto en el pasaje citado, la confiabilidad del orador se construye internamente, indiferente al juicio externo que se tenga sobre él. ${ }^{57}$ Para ello, debe demostrar - “aparentar" en sentido estricto- ${ }^{58}$ estar provisto de tres cualidades que son las constitutivas

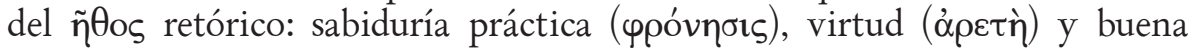
disposición o benevolencia ( $\varepsilon u ́ v o r \alpha)(R h .1378 a 8) .{ }^{59}$ Ninguna de las tres puede faltar si se quiere ser persuasivo: “... es forzoso que el que parezca tener todas

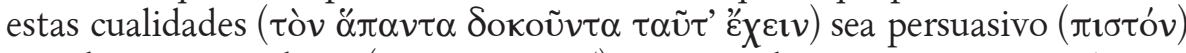
para los que escuchan" ( $R$. 1378a14-5). De acuerdo con esta concepción que concede al $\tilde{\eta} \theta$ os un estatus discursivo e inmanente, se vuelve fundamental la autopresentación de Bátaro. Se hace necesario determinar si se manifiesta munido, o no, de la totalidad de las cualidades consignadas por el Estagirita.

Hemos precisado ya que Bátaro, no bien comenzado su alegato, se ocupa de dar testimonio de su buena voluntad ( $\varepsilon u ̛ v o r \alpha)$, manifestándose amigo y benefactor del pueblo (16-20). La Retórica a Alejandro aconseja manifestar la عưvor $\alpha$ precisamente con acciones comunitarias, mostrándose

57 En este punto la Retórica aristotélica resulta original y rompe con la tradición que asociaba la fuerza persuasiva del orador con el carácter real del que hablaba, en la creencia de que una vida virtuosa está indisolublemente unida a la aptitud de pensar y hablar bien. Esta idea es precisamente la que se desprende de la Retórica a Alejandro cuando se expresa acerca de la adecuación del estilo al carácter del orador (cf. $R h . A l$. 1434b26-30). Frente a este valor referencial del $\tilde{\eta} \theta$ os del orador, Aristóteles propone en cambio una teoría del $\tilde{\eta} \theta$ os inmanente al discurso. Véase al respecto, F. Woerther, Lèthos aristotélicien. Genèse d'une notion rhétorique, Paris 2007, especialmente 91-4. La autora se ocupa de revisar diacrónicamente los empleos heterogéneos, e irreductibles unos de otros, que ha tenido la palabra $\tilde{\eta} \theta$ os desde los textos homéricos hasta el s. IV. En el s. V el término oscilaba entre la designación de un estado natural y otro relacionado con la educación y las costumbres. El concepto atraviesa los escritos aristotélicos políticos, poéticos y éticos, con usos y sentidos también diversos.

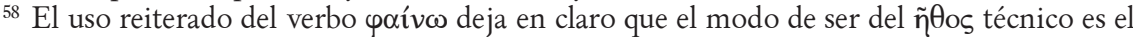
de la apariencia, cf. $R h$. 1366a10-12 y 1378a15-16.

${ }^{59}$ En principio menciona solo dos de estas cualidades (Rh. 1.8), "virtud" y "benevolencia", y su presencia podía no ser simultánea. W. Fortenbaugh, "Aristotle on Persuasion through Character”, Rhetorica 10.3, 1992, 207-44, juzga que Aristóteles no es original en la idea de la persuasión a través del carácter, sino que, por el contrario, continúa toda una tradición literaria, entre la que se encuentran el homérico Néstor y el Pericles tucidídeo. También señala como antecedente el Gorgias de Platón, donde se reconoce la importancia de la tríada 'sabiduría, virtud y benevolencia'. Woerther, L'èthos aristotélicien, por su parte, prefiere subrayar la innovación que supone la concepción del Estagirita en el tema y relacionar, en todo caso, con la noción del $\tilde{n} \theta$ os en las éticas del mismo autor. 
como buen consejero de la ciudad y bien predispuesto para el servicio público (RhAl.1436b22-6). ${ }^{60}$ Ahora bien, resulta poco menos que sorprendente calificar de contribución patriótica la provisión de prostitutas para la ciudad. El particular código de honor del burdelero colisiona a todas luces con los valores cívicos de la época. Aunque sus palabras tienen sin duda un buscado

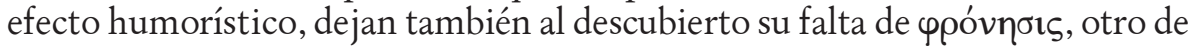
los forzosos condicionamientos morales para influir en el público. En efecto,

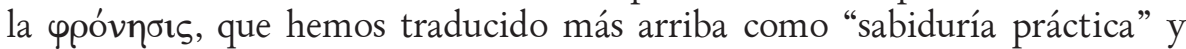
otros prefieren traducir por "prudencia", alude a la condición de deliberar con rectitud, "ya que por la falta de sentido práctico ( $\delta$ ' $\dot{\alpha} \varphi \rho o \sigma u ́ v \eta \eta)$ no se opina

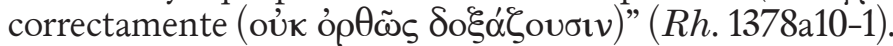

Cuando Bátaro se proclama orgullosamente un pervertido ("Soy un

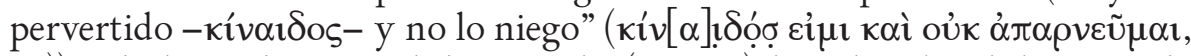
$74)$ ), vale decir, al margen de las virtudes (à $\rho \varepsilon \tau \alpha i ́)$ de un hombre de bien, revela una vez más su falta de prudencia. El kívoıßos era considerado un perverso y lascivo, un tipo social afeminado, situado socialmente en las antípodas de la masculinidad que encarnaba el ciudadano hoplita. ${ }^{61}$ En el Gorgias de Platón (494C-5A) es descripto como un homosexual pasivo, que no sabe controlar

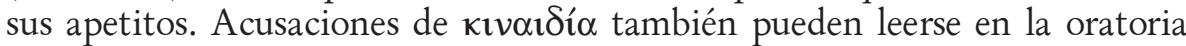
ática, pero solo en contextos de difamación, como sucede con Esquines (1.131, Contra Trimarco; y 2.88 y 99, Sobre la embajada fraudulenta), que señala la vestimenta y el estilo de vida de Demóstenes como ejemplo de kıvaı $\delta i ́ \alpha .{ }^{62}$ En Bátaro, en cambio, resulta una muestra de insensata jactancia. La misma que se manifiesta cuando dice sentirse honrado de sus antepasados, todos ellos también burdeleros: "Mi abuelo era Sisímbrade y mi padre Sisimbrisco, y todos tenían prostíbulos...", 76-7.63 El hecho de mencionar la genealogía como prueba de rectitud formaba parte de los topoi de la oratoria de las cortes. Bátaro, sin embargo, está más cerca de los personajes de comedia, que también mencionan con orgullo actividades y profesiones despreciadas por la sociedad (cf. las palabras del delator en Aves 1451-2: "No voy a avergonzar a mi familia. Ser un delator es un medio de vida heredado de mi padre").

Por lo demás, lo que Bátaro dice de sí mismo se ve respaldado por sus actitudes y gestos. Se deja entrever que su único deseo, antes que el castigo

${ }^{60}$ El momento en que esta "buena voluntad" se expresa, en el momento del prólogo, alienta a verla más como una estrategia para provocar el favor de los jueces antes que como el afán de crear un $\tilde{\eta} \theta$ os persuasivo.

${ }^{61}$ De este modo lo define J. Winkler, "Laying Down the Law: The Oversight of Men's Sexual Behavior in Classical Athens", in The Constraints of Desire, New York 1990, 45-70.

${ }^{62}$ Los lexicógrafos antiguos han propuesto diferentes etimologías para kívaı $\delta$ os, haciéndolo

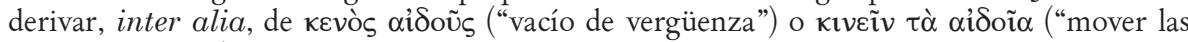
partes pudendas").

${ }^{63}$ Se trata de nombres afeminados, derivados de oıoú $\mu \beta \rho \imath o v$, que designa la "menta salvaje", usada en las guirnaldas. Los nombres de flores son normalmente adjudicados a cortesanas (cf. Ath. 587F). 
del reo, es obtener una ventaja económica a partir de lo ocurrido (él mismo afirma que levantaría la acusación si Tales pagara, 82, 89-90); su conducta se muestra ajena al espíritu moralista de las cortes. En la misma dirección debería interpretarse el trato familiar -e irrespetuoso- para con el encargado

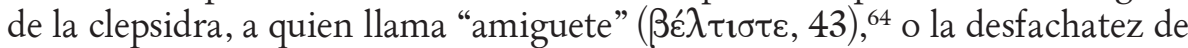
aconsejar a los jueces cómo proceder mejor en el juicio (99). Por todo lo cual, enfocado el asunto desde la Retórica aristotélica, Bátaro no acierta en valerse de la mediación persuasiva del $\tilde{\eta} \theta$ os, que exige aparentar ser una persona virtuosa, prudente y con buenas intenciones.

Por otro lado, el término $\tilde{\eta} \theta 0 \varsigma$ se emplea también en la Retórica de Aristóteles con un sentido diverso, vinculado con la caracterización del personaje en lo que atañe al estilo, es decir, con la idea de que la adecuación

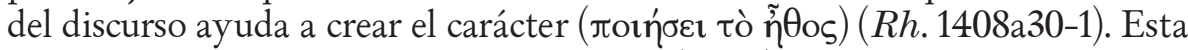
adaptación se extiende a la especie o clase ( yével) del orador -edad, género, o etnia-, y a su estado moral (ع̌ $\xi \varepsilon$ ) -que hace que cada uno sea el tipo de persona que es en su vida-: "Un rústico y una persona educada no diría lo

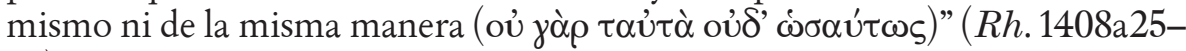
$32) .{ }^{65}$ Como se ve, remite a una realidad muy distinta a la del $\tilde{\eta} \theta$ os persuasivo, y su peso retórico es ciertamente menor ${ }^{66}$ En tal sentido, el comportamiento de Bátaro responde a las expectativas de un estilo apropiado ( se esperaría que un rufián hablara o actuara de forma distinta. Para decirlo de otro modo, Bátaro queda atrapado en un lugar de tensiones no resueltas porque, mientras su retrato resulta dramáticamente adecuado y apropiado en cuanto al estilo, al mismo tiempo, la asunción de una vida alejada de toda virtud, en lo privado como en lo social, significa dejar de lado el mandato de crear una imagen positiva de sí mismo, de construir un $\tilde{\eta} \theta$ os técnicamente persuasivo. Precisamente el alegato de Bátaro pierde confiabilidad -y esto nos interesa destacar- porque no logra crear una impresión moral positiva a través de su discurso. En esta consideración no entra en juego la mala fama

${ }^{64}$ Los oradores se dirigen siempre con distancia y respeto a quien piden lea la ley.

${ }^{65}$ La tipología de caracteres según edad o fortuna que ofrece Aristóteles en $R h$. 2.12-17 podría formar un tratado autónomo en sí mismo y, según Woerther, L’èthos aristotélicien, podría responder a una resistematización operada en virtud de la popularidad de la doctrina de la verosimilitud o adecuación (eíkós) procedente de la retórica tradicional. No debería descartarse que este tratado formara un todo homogénero con el de las pasiones.

${ }^{66}$ ¿Con cuántos sentidos emplea Aristótles el término $\tilde{\eta} \theta 0 s$ en la Retórica? F. Worther, "Aux origine de la notion d'èthos", REG 118, 2005, 95, distingue dos: "Cette notion [ñ 0 os] renvoie, dans le traité, à deux réalités distinctes : elle désigne le caractère persuasif de l'orateur, qui recouvre trois vertus spécifiques, et fait également référence au "caractère ", dénué cette fois de toute valeur normative, qui fait l'objet de l'étude menée à travers les chapitres II, 12-17”. G.A. Kennedy, The Art of Persuasion in Greece, Princeton 1963, propone tres valores distintos: el que tiene que ver con la credibilidad del orador, el relacionado con la $\eta^{\prime} \theta$ ototí $\alpha$, y el que repara en el auditorio al cual el orador debe adaptar su argumentación. Otros autores, como W. Grimaldi, Aristotle. A Commentary, New York 1988, II, han elevado el número a cinco. 
social -o literaria- del rufián, ya que, a la luz de la Retórica aristotélica, los prejuicios podían ser lógicamente desarticulados por medio de la argumentación. Es entonces el propio Bátaro el que mina desde dentro toda posibilidad de ser creíble ( $\pi \imath \tau$ tóv $R h .1378$ a15), porque los que proceden como él, dirá Aristóteles, "engañan acerca de lo que dicen o aconsejan" Rh.1378a9).

Para finalizar, concluimos que Bátaro, a la luz de los tratados de retórica que hemos venido comentando, ha sabido argumentar desde un punto de vista lógico con idoneidad, valiéndose de muchos de los recursos habituales de la oratoria forense. Asimismo, ha buscado conmover emocionalmente a los jueces despertando las pasiones recomendadas para ponerlos de su lado. Sin embargo, no acierta en crear una impresión favorable de su propio carácter, y ello puede explicar por qué, como ha sostenido mayormente la crítica, no logra ser convincente. En lugar de construir una imagen conforme a los valores éticos de su auditorio, genera su desconfianza a favor de asumir con sinceridad extrema su falta de prudencia y de cualidades virtuosas. El hecho resulta altamente paradójico, si tenemos en cuenta que una de las principales características del tipo del rufián era su propensión al engaño; hubiera podido inventarse un retrato digno de fe para sus oyentes. Aristóteles le ha otorgado al $\tilde{\eta} \theta$ os un lugar central entre los medios de persuasión artísticos, y Bátaro falla porque ignora su valor y resta así fuerza persuasiva a su discurso. Es más, su alegato podría constituirse en una prueba de lo que el mismo filósofo advierte, esto es, que "el $\tilde{\eta} \theta$ os conlleva la forma de persuasión de mayor



${ }^{67}$ Aristóteles hace esta contundente afirmación con respecto al valor del $\tilde{\eta} \theta$ os en el discurso deliberativo; el mimo 2 probaría que también puede aplicarse al discurso judicial. 